\title{
МЕТОД ОБРОБКИ КОГЕРЕНТНИХ СИГНАЛІВ В МУЛЬТИРАДАРНІЙ СИСТЕМІ ОДНОТИПНИХ ДВОКООРДИНАТНИХ ОГЛЯДОВИХ РАДІОЛОКАЦІЙНИХ СТАНЦІЙ 3 МЕХАНІЧНИМ ОБЕРТАННЯМ
}

\begin{abstract}
Предметом вивчення в статті є задача розробки методу обробки когерентних сигналів в мультирадарній системі однотипних двокоординатних оглядових радіолокаційних станцій з механічним обертанням. Метою є підвищення ефективності виявлення повітряних об'єктів за рахунок об'єднання однотипних двокоординатних радіолокаційних станиій в мультирадарну систему. Запропоновано об'єднати існуючі оглядові радіолокаційні станції у просторово-рознесену когерентну мультирадарну систему. Проведено синтез оптимального виявлювача когерентних сигналів. Проведено оцінку характеристик виявлення повітряних об'єктів в мультирадарній системі з взаємно когерентними сигналами. Отримані результати: найбільшу ефективність і виграш у відношенні сигнал/шум показало додавання другої радіолокаційної станиії, оптимальна кількість радіолокаційних станцій у складі мультирадарної системи не більше чотирьох. Очікуємий виграш у пороговому відношенні сигнал/шум може складати до вісімнадцяти децибел. Використання більше чотирьох РЛС недоиільно.
\end{abstract}

Ключові слова: радіолокаційна станція, мультирадарна система, повітряний об’єкт, когерентна обробка, крива виявлення, імовірність правильного виявлення, імовірність хибної тривоги.

\section{Вступ}

Постановка проблеми у загальному вигляді. В умовах ведення сучасних гібридних та мережецентричних війн, антитерористичної операції (АТО) та операції Об'єднаних сил (ООС) на сході України побудова надійної системи протиповітряної оборони (ППО) взагалі та іiі розвідувально-інформаційної підсистеми зокрема, значно ускладнюється через появу малопомітних (з низьким рівнем радіолокаційного контрасту) та малорозмірних повітряних об'єктів (ПО) [1-2].

3 досвіду ведення АТО та ООС відомо, що малорозмірні БПЛА в більшості випадків не виявлялися наявними засобами радіолокації радіотехнічних військ (РТВ) [2-7], які складають основу розвідувально-інформаційної підсистеми ППО. Суттєво знижують ефективність застосування РТВ наступні проблеми [3]:

- система радіолокаційної розвідки (РЛР) не спроможна забезпечити гарантоване виявлення та супроводження ПО в цілому та малопомітних об'єктів, зокрема;

- відсутність достатньої кількості нових та модернізованих зразків радіоелектронної техніки, засобів автоматизації збору, обробки та видачі радіолокаційної інформації (РЛІ) в радіотехнічних підрозділах для забезпечення інформацією про ПО на малих та гранично малих висотах та інші.

Світові та вітчизняні виробники радіолокаційної техніки впроваджують останні досягнення науки i техніки: послідовно-паралельний електронний огляд зони по куту місця та двомірне електронне сканування діаграми спрямованості антени (ДСА), адаптивні фазовані антенні решітки (ФАР), цифровий синтез зондуючих сигналів 3 різними параметрами, цифрове діаграмоутворення [4-6].

У теперішній час на озброєння РТВ Повітряних Сил (ПС) Збройних Сил (ЗС) України надходять новітні та модернізовані зразки РЛС, у тому числі з широкосмуговими фазокодоманіпульованими сигналами та цифровими ФАР, але це процес поступовий та коштовний. Тому в цілому наявна техніка підрозділів не забезпечує повністю вирішення покладених на підрозділи завдань, особливо в частині, що стосується виявлення малопомітних ПО.

У той же час на озброєнні радіотехнічних підрозділів знаходиться велика кількість оглядових двокоординатних РЛС “старого” парку типу П-18. Указані РЛС не спроможні забезпечити виявлення сучасних малопомітних ПО з заданими показниками якості [5].

Таким чином, у теперішній час при вирішенні задачі виявлення малопомітних ПО загострилася невідповідність між тенденціями розвитку ПО та можливостями існуючих РЛС щодо виявлення малопомітних ПО з необхідною ефективністю.

Для вирішення указаної невідповідності та підвищення ефективності виявлення малопомітних ПО запропоновано об'єднати існуючі оглядові двокоординатні РЛС в когерентні МРС з сумісною обробкою сигналів [8-10].

Мета статті - розробка методу обробки когерентних сигналів в мультирадарній системі однотипних двокоординатних оглядових РЛС з механічним обертанням. 
Аналіз останніх досліджень і публікацій. На сьогоднішній день задачі пошуку та виявлення малопомітних ПО вирішуються шляхом ведення спостереження, використанням радіотехнічних, інфрачервоних, оптичних та акустичних засобів розвідки.

Проте застосування радіолокаційних засобів розвідки має свої беззаперечні переваги перед вищезазначеними способами [11-12]. Окрім відомих методів радіолокації в останні роки ведуться розробки та широко застосовуються нетрадиційні: використання сторонніх джерел підсвіту, з використанням ефекту “радіолокації на просвіт”, застосуванням пасивно-активних радіолокаційних комплексів та інші.

Перераховані методи засновані на загальній тенденції у розвитку техніки - об'єднанні окремих пристроїв (засобів) у системи. Відомо, що існує цілий ряд різних типів мультирадарних систем. Окремі позиції елементів таких систем просторово рознесені одна від одної, при цьому обробка РЛІ проводиться в центральному пункті обробки, який може бути суміщений $з$ однією 3 позицій або розташований окремо. В такому пункті доцільно проводити сумісну обробку радіолокаційної інформації, ефективність якої залежить від ступеню когерентності, яка забезпечується в системі [11-14]. У роботі запропоновано об'єднати існуючі оглядові двокоординатні РЛС у синхронну когерентну мультирадарну систему згідно з методом, що викладено у [8], та пояснюється алгоритмом, наведеним на рис. 1.

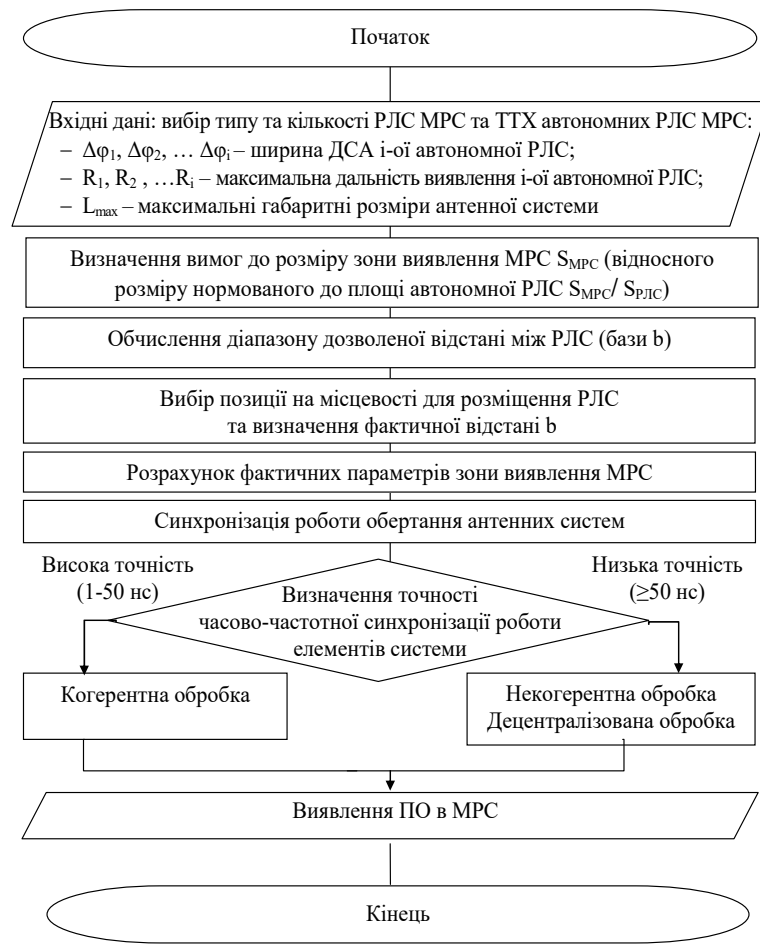

Рис. 1. Метод формування узгодженої зони огляду малобазової МРС однотипних оглядових РЛС з механічним обертанням

\section{Виклад основного матеріалу}

Створення МРС дає можливість вирішити завдання збільшення енергетичного потенціалу РЛС, збільшення коефіцієнту підсилення антенних систем або використання системних ефектів. Використання системних ефектів при об'єднанні автономних РЛС в МРС пов'язано з можливостями реалізації різного ступеню когерентності просторово рознесених позицій та сумісним прийомом ехосигналів [9-15].

Одним 3 ключових питань, що визначають можливість створення синхронно-когерентної МРС 3 просторово-рознесених РЛС, $є$ необхідність виконання умов:

- синхронізація по частоті;

- синхронізація по фазі;

- синхронізація по часу;

- узгоджений огляд простору.

На рис. 2 наведено приклад побудови МРС.

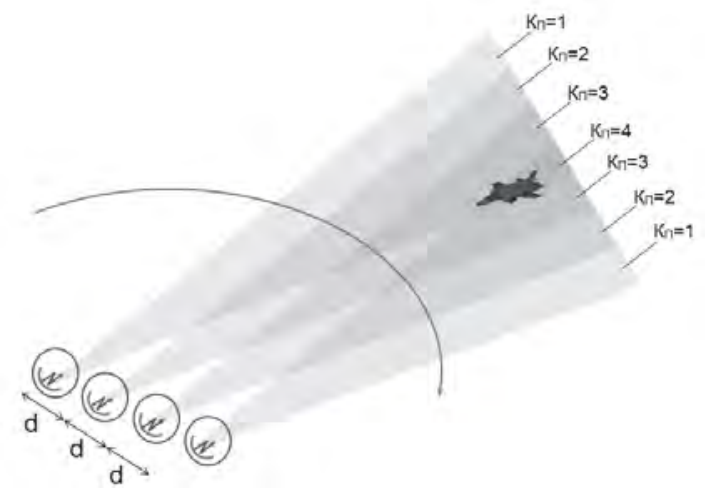

Рис. 2. Приклад побудови синхронної малобазової МРС 3 4-х РЛС

Кожна РЛС випромінює свій зондувальний сигнал (3С), який не корельований із 3С інших РЛС. Сигнали усіх РЛС випромінюються одночасно. Не корельованість (ортогональність) може забезпечуватися за рахунок:

- рознесення по частоті (частотна);

- кодування сигналів (кодова).

Кожна РЛС приймає ехо сигнали:

- свій ЗС, відбитий від ПО;

- відбитий від ПО ЗС сусідніх РЛС.

Розглянемо МРС, у складі якої кожна РЛС випромінює взаємно ортогональні сигнали. Ці сигнали відбиваються від ПО складної форми. У разі, якщо розміри ПО набагато більше довжини хвилі, сигнали, що приймаються кожною РЛС, флуктуюють. Як правило, флуктуації амплітуди описуються релєєвським законом, а флуктуації фази рівномірно розподілені в інтервалі $(-\pi, \pi)$. Характер флуктуації сигналів, які приймаються різними РЛС, залежить від ступеню їх просторової кореляції, яка обумовлюється розміром ефективної бази (відстані) між РЛС (виpaз (1)): 


$$
\frac{L_{e \phi}}{R}>(0.8 \ldots 1) \frac{\lambda}{l_{\Pi О}},
$$

де $L_{e \phi}=L \sin (\theta)$ - ефективна база між просторово рознесеними РЛСі та РЛСј ( $\theta$ - кут, що визначає напрямок на ПО);

$R$ - дальність до ПО від середини ефективної бази;

$\lambda$ - довжина хвилі РЛС;

$l_{\text {По }}$ - поперечний розмір ПО (паралельний ефективній базі).

При повній просторовій кореляції комплексні амплітуди та початкові фази сигналів на входах різних позицій міцно зв'язані та флуктуюють дружно. Тому такі сигнали - просторово-когерентні. При малих базах між приймальними позиціями можливий жорсткий зв'язок між комплексними амплітудами ехосигналів в різних позиціях (повна часова кореляція).

На вхід приймача РЛС в кожній позиції поступають сигнали, що випромінюються усіма РЛС.

Якщо усіма РЛС здійснюється випромінювання однакових сигналів таким чином, що забезпечується ïх синфазне сумування на ПО, то на вході приймальних позицій буде тільки один ехо-сигнал. Ефективне значення амплітуди ехо-сигналу в цьому випадку буде дорівнювати сумі ефективних значень ехосигналів, утворених всіма передавальними позиціями [11-13].

В цьому випадку обробка здійснюється над $M$ реалізацій незалежних гаусівських процесів. Середнє значення цих процесів в кожній приймальній позиції дорівнює сфазованій сумі $M$ ехо-сигналів. Вихідне значення сигнал-шум при цьому визначається виразом (2):

$$
q_{\text {Bux }}^{2}=N M^{2} q_{\text {вux } 0}^{2},
$$

де $q_{\text {вих } 0}^{2}$ - відношення сигнал-шум за потужністю на виході однопозиційної РЛС;

$N$ - кількість РЛС, які працюють в приймальнопередавальному режимі;

$M$-реалізацій незалежних гаусівських процесів.

Додатковий виграш в $M$ разів пояснюється тим, що при синфазному складанні сигналів на ПО не беруть участь шуми приймача, а при когерентному складанні в приймальних пристроях разом з сигналами некогерентно складаються шуми.

Метод обробки когерентних сигналів в МРС однотипних двокоординатних оглядових РЛС з механічним обертанням запропоновано у вигляді, представленому на рис. 3 .

При когерентному підсумовуванні сигналів та лінійному детектуванні вихідна статистика має розподіл Релєя, а при квадратичному детектуванні експоненціальний розподіл імовірностей.

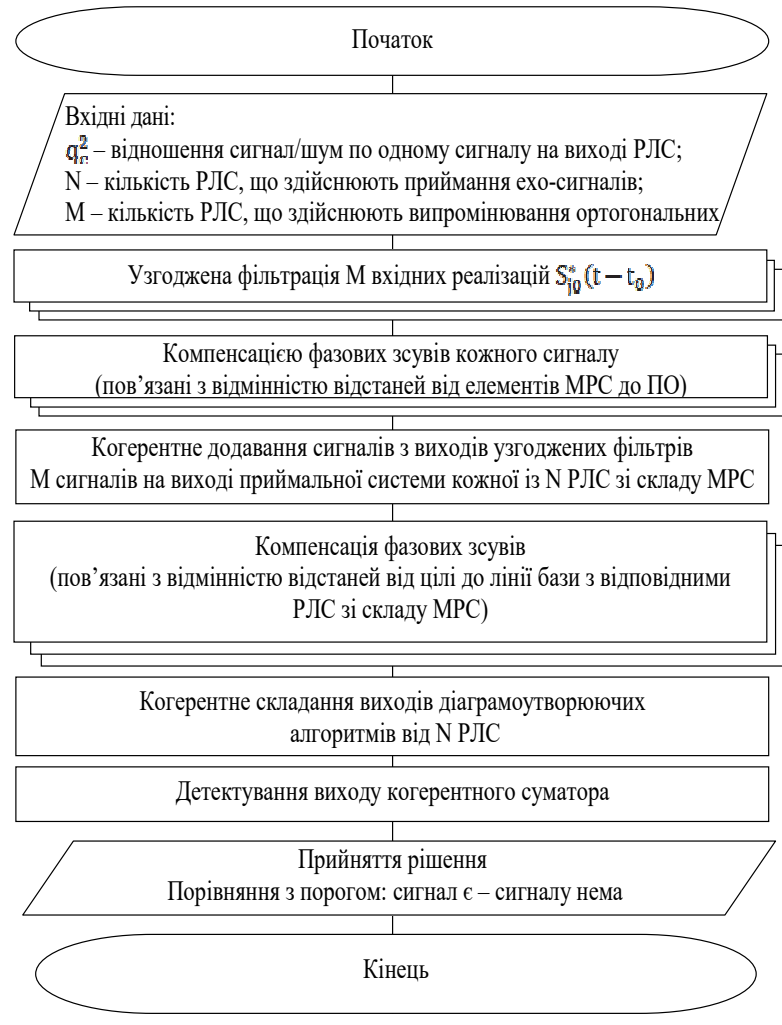

Рис. 3. Метод обробки когерентних сигналів в МРС

Для побудови кривих виявлення в обох випадках зручно використовувати відомий вираз для імовірності правильного виявлення та хибної тривоги (вираз (3)):

$$
P_{B}=P_{x m}^{1 /\left(1+\overline{q_{\text {Bux }}^{2}}\right)},
$$

де $P_{B}$ - імовірність правильного виявлення;

$P_{X T}-$ імовірність хибної тривоги;

$q_{\text {вux }}^{2}$ - відношення сигнал/шум на вході порого-вого пристрою, яке визначається в залежності від особливостей побудови просторово-когерентної MPC.

На рис. 4 наведено криві виявлення для малобазової просторово-когерентної МРС.

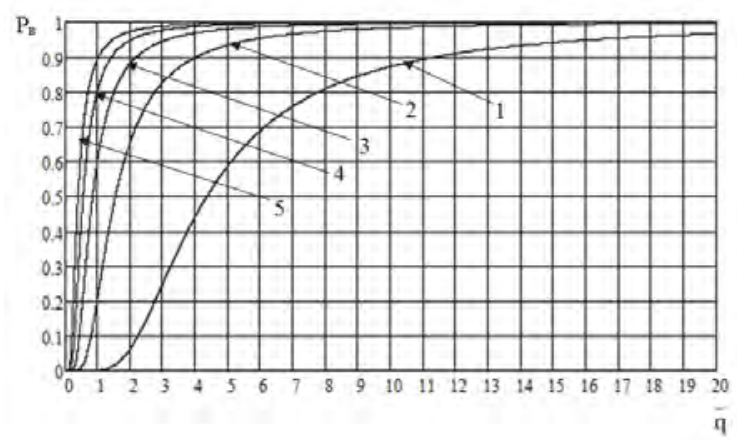

Рис. 4. Характеристики виявлення МРС:

1 - для автономної РЛС; 2 - при використанні 2-х

РЛС в МРС; 3 - при використанні 3-х РЛС в МРС; 4 - при використанні 4-х РЛС в МРС; 5 - при використанні 5-х РЛС в МРС 
На рис. 4 наведено випадок, коли усі однотипні РЛС малобазової просторово-когерентної МРС використовують однакові сигнали таким чином, що забезпечується їх синфазне сумування на ПО та на вході приймальних позицій отримаємо тільки один ехо-сигнал. Наведено розрахунки при роботі однієї автономної РЛС та при використанні МРС із декількох РЛС для імовірності хибної тривоги $P_{X T}=10^{-6}$.

Із аналізу характеристик виявлення, зображених на рис. 4, видно, що перехід від автономної РЛС (крива 1) до об'єднання двох-трьох РЛС (криві 2, 3) приводить до суттєвого зсуву характеристик виявлення ліворуч. Збільшення кількості РЛС, що об'єднуються когерентно, більше трьох (криві 4, 5) не приводять до суттєвого зсуву характеристик виявлення ліворуч у порівнянні із характеристикою виявлення при об'єднанні трьох РЛС (крива 2).

На рис. 5 наведено залежність виграшу $K(m)$ у потрібному відношенні сигнал/шум в кожної $3 \mathrm{~m}$ РЛС зі складу МРС відносно автономної РЛС для забезпечення показників якості виявлення ПО в просторово-когерентній МРС $\left(P_{B}=0,5, P_{X T}=10^{-6)}\right.$ при когерентному об'єднанні РЛС від кількості РЛС $(m)$, що об'єднуються.

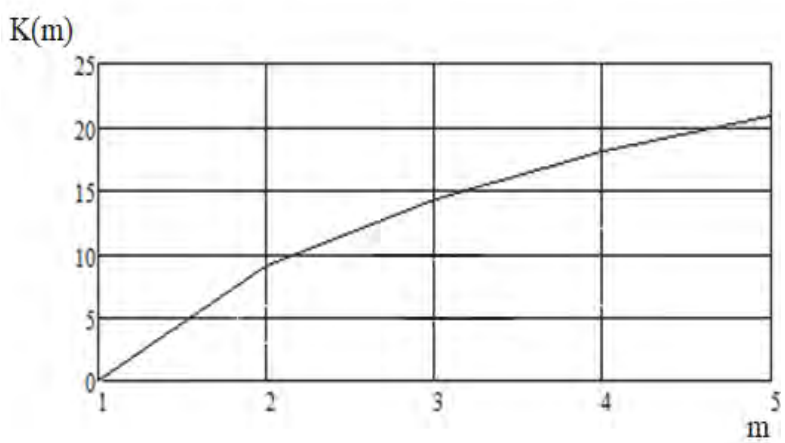

Рис. 5. Залежність виграшу у відношенні сигнал/шум в просторово-когерентної МРС

у випадку, коли усі РЛС використовують однакові сигнали таким чином, що забезпечується їх синфазне сумування на ПО

Із аналізу залежності виграшу у відношенні сигнал/шум, наведеної на рис. 5, видно, що для випадку, коли усі однотипні РЛС малобазової просторовокогерентної МРС використовують однакові сигнали таким чином, що виникає їх синфазне сумування на ПО 3 отриманням на вході приймальних позицій тільки одного ехо-сигналу, забезпечується виграш біля 10 дБ при об'єднанні двох РЛС, і біля 5 дБ з додаванням третьої РЛС, а збільшення виграшу лише на 2,5 дБ 3 додаванням четвертої РЛС і більше РЛС також забезпечують зростання виграшу, але швидкість цього зростання значно менша, що погіршує практичну значущість та економічну доцільність. Отже, підсумовуючи вище зазначене, можна зробити висновок, що найбільша ефективність у виграші у відношенні сигнал/шум при об’єднанні однакових просторово-розподілених РЛС в когерентну МРС спостерігається при переході від роботи однієї автономної РЛС до МРС з двома-трьома РЛС. Подальше збільшення кількості РЛС у всіх трьох випадків супроводжується зменшенням ефективності від додавання кожної наступної РЛС і практично недоцільним є використання у складі МРС більше чотирьох РЛС при максимально можливому виграші на рівні близька 2 дБ з додаванням останньої РЛС у порівнянні з майже 10 дБ при переході від однієї РЛС до МРС $з$ двома РЛС.

Найбільшу ефективність у виграш у відношенні сигнал/шум показало додавання другої РЛС і всі випадки показали оптимальну кількість РЛС у складі МРС не більше чотирьох.

Отже, за критерієм ефективність-вартість найбільш ефективним $\epsilon$ створення просторовокогерентної МРС шляхом об'єднання від двох до чотирьох однотипних РЛС.

Таким чином, для підвищення якості виявлення малопомітних ПО доцільно створювати просторовокогерентну МРС шляхом об'єднання від двох до чотирьох оглядових РЛС. При цьому очікуємий виграш у пороговому відношенні сигнал/шум може складати до 17 дБ. Використання більше чотирьох РЛС недоцільно, оскільки це не приводить до істотного збільшення виграшу.

\section{Висновки}

Таким чином, можна стверджувати, що найбільшу ефективність у виграш у відношенні сигнал/шум показало додавання другої РЛС і оптимальну кількість РЛС у складі МРС не більше чотирьох.

Отже, за критерієм ефективність-вартість найбільш ефективним $\epsilon$ створення просторовокогерентної МРС шляхом об'єднання від двох до чотирьох однотипних РЛС.

Таким чином, для підвищення якості виявлення малопомітних ПО доцільно створювати просторовокогерентну МРС шляхом об'єднання від двох до чотирьох оглядових РЛС. При цьому очікуємий виграш у пороговому відношенні сигнал/шум може складати до 18 дБ. Використання більше чотирьох РЛС недоцільно, оскільки це не приводить до істотного збільшення виграшу. Була введена у розгляд поточна.

Напрямком подальших досліджень є розгляд методу виявлення ПО у випадку використання в МРС 3 просторово-рознесених РЛС ортогональних взаємно некогерентних $3 \mathrm{C} \quad 3$ їх подальшою обробкою. 


\section{Список літератури}

1. Banasik M. How to understand the Hybrid War / M. Banasik // Securitologia. - 2015. - № 1. - P. 19-34.

2. Алімпієв А.М. Особливості гібридної війни РФ проти України. Досвід, що отриманий Повітряними Силами Збройних Сил України / А.М. Алімпієв, Г.В. Пєвцов // Наука і техніка Повітряних Сил Збройних Сил України. - 2017. № 2(27). - C. 19-25. https://doi.org/10.30748/nitps.2017.27.03.

3. Світові тенденції розвитку радіолокаційних засобів контролю повітряного простору / О.В. Бєлавін, В.Й. Климченко, Г.Г. Камалтинов, О.С. Маляренко // Наука і оборона. - 2015. - № 1. - С. 48-53.

4. Dave Hill. Multi-Static Primary Surveillance Radar - An examination of Alternative Frequency Bands [Electronic resource] / Dave Hill, Philip Galloway // Report of EUROCONTROL. - Issue 1.2. - 183 p. - Available at: $\mathrm{http}$ //www.eurocontrol.int/sites/default/files/content/documents/nm/mspsr study report. pdf (дата звернення 21.09.2017).

5. Шамко С.В. Основні особливості застосування Повітряних Сил в сучасних умовах ведення збройної боротьби / С.В. Шамко, О.М. Жарик, В.В. Коваль // Наука і техніка Повітряних Сил Збройних Сил України. - 2017. - № 2(27). C. 15-18. https://doi.org/10.30748/nitps.2017.27.02.

6. Алімпієв А.М.Довідник учасника АТО: озброєння і військова техніка Збройних Сил Російської Федерації / А.М. Алімпієв, Г.В. Пєвцов, Д.А. Гриб. - Х.: Оригінал, 2015. - 732 с.

7. Ліщенко В.М. Малорозмірні безпілотні літальні апарати як об'єкти радіолокаційної розвідки / В.М. Ліщенко, В.В. Чалий, А.Д. Карлов // Системи управління, навігації та зв’язку. - 2016. - № 3(39). - С. 27-32.

8. Мультирадарна система оглядових радіолокаційних станцій з малою базою / Г.В. Худов, В.М. Ліщенко, В.О. Тютюнник, В.В. Чалий // Системи озброєння і військова техніка. - 2017. - № 4(52). - С. 123-128.

9. Method for the detection of smallsized air objects by observational radars / H. Khudov, A. Zvonko, S. Kovalevskyi, V. Lishchenko, F. Zots // Eastern-European Journal of Enterprise Technologies. - 2018. - № 2/9(92). - P. 61-68. https://doi.org/10.15587/1729-4061.2018.126509.

10. The Method of Increasing the Detection Range of Unmanned Aerial Vehicles in Multiradar Systems Based on Surveillance Radars / V. Lishchenko, H. Khudov, V. Tiutiunnyk, V. Kuprii, F. Zots, G. Misiyuk // 2019 IEEE 39th International Conference on Electronics and Nanotechnology (ELNANO), 2019. https://doi.org/10.1109/ELNANO.2019.8783263.

11. Chernyak V.S. Fundamentals of Multisite Radar Systems / V.S. Chernyak. - Gordon and Breach Science Publishers, 1998. $-475 \mathrm{p}$.

12. Radar Handbook. Third Edition / Editor in Chief Merill I. Skolnik. - USA: McGraw-Hill, 2008. - 1351 p.

13. Черняк В.С. О новом направлении в радиолокации / В.С. Черняк // Прикладная радиоэлектроника. - 2009. № 4 (том 8). - С. 477-489.

14. Петров В. Наземные РЛС ПВО стран НАТО [Електронний ресурс] / В. Петров, С. Гришулин // Зарубежное военное обозрение. - Режим доступу: http:// www.modernarmy.ru/article/173 (дата звернення 12.05.2017).

15. Advances in Bistatic Radar / Edited by Nicholas J. Willis, Hugh D. Griffiths. - SciTech Publishing Inc., 2007. - 515 p.

\section{References}

1. Banasik, M. (2015), How to understand the Hybrid War, Securitologia, No. 1, pp. 19-34.

2. Alimpiiev, A.M. and Pevtsov, G.V. (2017), "Osoblyvosti hibrydnoi viiny RF proty Ukrainy. Dosvid, shcho otrymanyi Povitrianymy Sylamy Zbroinykh Syl Ukrainy" [The features of the hybrid war of the Russian Federation against Ukraine. Experience received by the Air Forces of the Armed Forces of Ukraine], Science and Technology of the Air Force of Ukraine, No. 2(27), pp. 19-25. https://doi.org/10.30748/nitps.2017.27.03.

3. Belavin, A.V., Klimchenko, V.I., Kamaltynov, G.G. and Malyarenko, A.S. (2015), "Svitovi tendenciji rozvytku radiolokacijnykh zasobiv kontrolju povitrjanogho prostoru" [World trends in the development of radar means for control airspace], Science and Defense, No. 1, pp. 48-53.

4. Hill, Dave and Galloway, Philip (2017), Multi-Static Primary Surveillance Radar - An examination of Alternative Frequency Bands, Report of EUROCONTROL, Issue 1.2, 183 p., available at: www.eurocontrol.int/sites/default/files/content/documents/nm/mspsr study report. pdf. (accessed 21 September 2017).

5. Shamko, Ie.V., Zharyk, O.M. and Koval, V.V. (2017), “Osnovni osoblyvosti zastosuvannia Povitrianykh Syl v suchasnykh umovakh vedennia zbroinoi borotby" [Basic features of use of the Air Force under present-day conditions during armed struggle], Science and Technology of the Air Force of Ukraine, No. 2(27), pp. 15-18. https://doi.org/10.30748/nitps.2017.27.02.

6. Alimpiiev, A.M., Pevtsov, G.V. and Grib, D.A. (2015), "Dovidnyk uchasnyka ATO: ozbrojennja i vijsjkova tekhnika Zbrojnykh Syl Rosijsjkoji Federaciji" [Reference book of the participant of the ATO: weapons and military equipment of the Armed Forces of the Russian Federation], Original, Kharkiv, 732 p.

7. Lishchenko, V.M., Chaliy, V.V. and Karlov, A.D. (2016), "Malorozmirni bezpilotni litaljni aparaty - analiz zaghroz efektyvnosti vedennja radiolokacijnoji rozvidky" [Small unmanned aerial vehicles - threat analysis of efficiency of reference of radar reconnaissance ], Control, Navigation and Communication Systems, No. 3(39), pp. 27-32.

8. Khudov, H.V., Lishchenko, V.M., Tiutiunnyk, V.O. and Chaliy, V.V. (2017), "Multyradarna systema ohliadovykh radiolokatsiinykh stantsii z maloiu bazoiu" [Small radar multi-radar surveillance system with small base], Systems of Arms and Military Equipment, No. 4(52), pp. 123-128.

9. Khudov, H., Zvonko, A., Kovalevskyi, S., Lishchenko, V., and Zots, F. (2018), Method for the detection of smallsized air objects by observational radars, Eastern-European Journal of Enterprise Technologies, No. 2/9(92), pp. 61-68. https://doi.org/10.15587/1729-4061.2018.126509. 
10. Lishchenko, V., Khudov, H., Tiutiunnyk, V., Kuprii, V., Zots, F., and Misiyuk, G. (2019), The Method of Increasing the Detection Range of Unmanned Aerial Vehicles in Multiradar Systems Based on Surveillance Radars, IEEE 39th International Conference on Electronics and Nanotechnology (ELNANO). https://doi.org/10.1109/ELNANO.2019.8783263.

11. Chernyak, V.S. (1998), Fundamentals of Multisite Radar Systems, Gordon and Breach Science Publishers, 475 p.

12. Skolnik, Merill I. (2008), Radar Handbook, Third Edition, McGraw-Hill, USA, 1351 p.

13. Chernyak, V.S. (2009), "O novom napravlenyy v radyolokacyy" [About a new direction in radar], Applied electronics, No. 4, Vol. 8, pp. 477-489.

14. Petrov, V. and Grishulin, S. (2017), "Nazemnie radyolokatori protyvovozdushnoj oboroni stran NATO" [Ground-based air defense radars of NATO countries], Foreign military review, available at: www.modernarmy.ru/article/173 (accessed $12 \mathrm{Au}$ gust 2017).

15. Willis, Nicholas J. and Griffiths, Hugh D. (2007), Advances in Bistatic Radar, SciTech Publishing Inc., 515 p.

Надійшла до редколегії 10.02.2020

Схвалена до друку 17.03.2020

\section{Відомості про автора:}

\author{
Ліщенко Віталій Миколайович \\ ад'юнкт
}

Харківського національного університету

Повітряних Сил ім. I. Кожедуба,

Харків, Україна

https://orcid.org/0000-0002-8269-0089
Information about the author:

\author{
Vitaliy Lishchenko \\ Doctoral Student \\ of Ivan Kozhedub Kharkiv \\ National Air Force University, \\ Kharkiv, Ukraine \\ https://orcid.org/0000-0002-8269-0089
}

\title{
МЕТОД ОБРАБОТКИ КОГЕРЕНТНЫХ СИГНАЛОВ В МУЛЬТИРАДАРНОЙ СИСТЕМЕ ОДНОТИПНЫХ ДВУХКООРДИНАТНЫХ ОБЗОРНЫХ РАДИОЛОКАЦИОННЫХ СТАНЦИЙ С МЕХАНИЧЕСКИМ ВРАЩЕНИЕМ
}

\author{
В.М. Ліщенко
}

Предметом изучения в статье является задача разработки метода обработки когерентных сигналов в мультирадарной системе однотипных двухкоординатных обзорных радиолокационных станций с механическим вращением. Целью является повышение эффективности обнаружения воздушных объектов за счет объединения однотипных двухкоординатных радиолокаиионных станций в мультирадарну систему. Предложено объединить существующие обзорные радиолокационные станции в пространственно-разнесённую когерентную мультирадарную систему. Проведен синтез оптимального обнаружителя когерентных сигналов. Проведена оценка характеристик обнаружения воздушных объектов в мультирадарной системе с взаимно когерентными сигналами. Полученные результаты: наибольшую эффективность в выцгрыш в отношении сигнал/шум показало добавление второй радиолокачионной станции, оптимальное количество радиолокачионных станций в составе мультирадарной системы не более четырех. Ожидаемый выигрыш в пороговом отношении сигнал/шум может составлять до восемнадиати децибел. Использование более четырех РЛС нецелесообразно.

Ключевые слова: радиолокационная станция, мультирадарная система, воздушный объект, когерентная обработка, кривая обнаружения, вероятность правильного обнаружения, вероятность ложной тревоги.

\section{THE METHOD OF COHERENT SIGNALS PROCESSING IN MULTIRADAR SYSTEM OF SINGLE-TYPE TWO-ORDINATE SURVEY RADARS WITH MECHANICAL ROTATION}

\section{Lishchenko}

The subject of this article is the task of developing a method of processing coherent signals in a multi-radar system of the same two-coordinate radar observation stations with mechanical azimuth rotation. The goal of the paper is to solve the problem of developing a method of processing coherent signals in multi radar system topics of radar stations with mechanical rotation. It has been found that, in modern-day hybrid wars, building a reliable air defense system is made much more difficult by the appearance of low radar cross section aerial objects. It is proposed to increase the energy potential of existing radar observation stations by integrating them into a spatially spaced coherent multi-radar system. To ensure a consistent overview of the airspace, the locations of the radar stations are made in a single line with their synchronous azimuth rotation. The sounding signals must be simultaneously transmitted and orthogonal by frequency diversity or encoding. The synthesis of the optimal coherent signal finder is performed. The characteristics of detection of air objects in a multi-radar system with mutually coherent signals are evaluated, when all radar stations emit identical signals in such a way that their common-purpose summation is secured. The following results were obtained: the highest efficiency in signal / noise gain was shown by the addition of a second radar station, the optimum number of radars in the multi-radar system of no more than four. Therefore, the most cost-effective criterion is to create a spatially coherent multi-radar system by combining two to four similar radars. In this case, the expected gain in the threshold signal-to-noise can be up to eighteen decibels. The use of more than four radars is impractical because it does not lead to a significant increase in the gain. The direction of further researches is the development of a method of processing incoherent mutually orthogonal signals in a multiradar system-space spatially spaced two-coordinate radar observation stations with mechanical azimuth rotation.

Keywords: radar, multi radar system, air object, coherent processing, detection curve, probability of correct detection, probability of false alarm. 